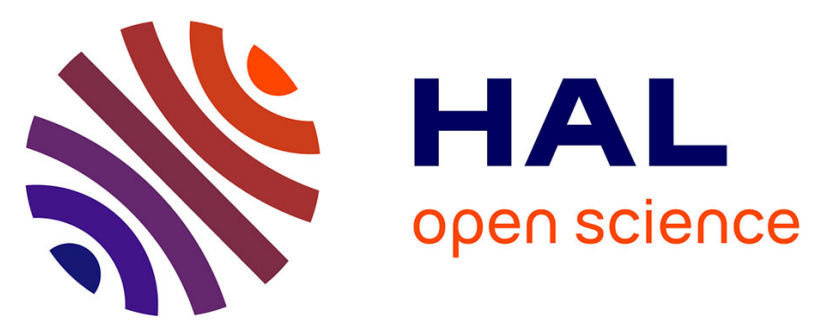

\title{
Hepatitis B surface antigen quantification as a predictor of seroclearance during treatment in HIV-hepatitis B virus coinfected patients from Sub-Saharan Africa
}

Anders Boyd, Sarah Maylin, Raoul Moh, Nadia Mahjoub, Delphine Gabillard, Serge Paul Eholié, Christine Danel, Xavier Anglaret, Fabien Zoulim, Pierre-Marie Girard, et al.

\section{To cite this version:}

Anders Boyd, Sarah Maylin, Raoul Moh, Nadia Mahjoub, Delphine Gabillard, et al.. Hepatitis B surface antigen quantification as a predictor of seroclearance during treatment in HIV-hepatitis B virus coinfected patients from Sub-Saharan Africa. Journal of Gastroenterology and Hepatology, 2016, 31 (3), pp.634-644. 10.1111/jgh.13156 . hal-01288716

\section{HAL Id: hal-01288716 https://hal.sorbonne-universite.fr/hal-01288716}

Submitted on 16 Mar 2016

HAL is a multi-disciplinary open access archive for the deposit and dissemination of scientific research documents, whether they are published or not. The documents may come from teaching and research institutions in France or abroad, or from public or private research centers.
L'archive ouverte pluridisciplinaire HAL, est destinée au dépôt et à la diffusion de documents scientifiques de niveau recherche, publiés ou non, émanant des établissements d'enseignement et de recherche français ou étrangers, des laboratoires publics ou privés. 
Hepatitis B surface antigen quantification as a predictor of seroclearance during treatment in HIVhepatitis B virus co-infected patients from Sub-Saharan Africa

Anders Boyd ${ }^{1}$, Sarah Maylin ${ }^{2,3,4}$, Raoul Moh ${ }^{5}$, Nadia Mahjoub ${ }^{2,3}$, Delphine Gabillard ${ }^{6,7}$, Serge Paul Eholié ${ }^{5,8}$, Christine Danel ${ }^{5,6,7}$, Xavier Anglaret ${ }^{5,6,7}$, Fabien Zoulim ${ }^{9}$, Pierre-Marie Girard ${ }^{10,11}$, Constance Delaugerre ${ }^{2,3,4}$, Karine Lacombe ${ }^{10,11}$ for the ANRS 12240 VarBVA study

\section{Institutional affiliations:}

${ }^{1}$ INSERM, UMR_S1136, Institut Pierre Louis d’Epidémiologie et de Santé Publique, Paris, France;

${ }^{2}$ Laboratoire de Virologie, Hôpital Saint-Louis, AP-HP, Paris, France;

${ }^{3}$ INSERM U941, Paris, France;

${ }^{4}$ Université Paris-Diderot, Paris, France;

${ }^{5}$ Programme PAC-Cl, ANRS Research Site, Treichville University Hospital, Abidjan, Côte d'Ivoire;

${ }^{6}$ INSERM, U897, Epidémiologie-Biostatistique, Bordeaux, France;

${ }^{7}$ University of Bordeaux, ISPED, Bordeaux, France;

${ }^{8}$ Department of Infectious and Tropical Diseases, Treichville University Teaching Hospital, Abidjan, Côte d'Ivoire;

${ }^{9}$ Centre de Recherche sur le Cancer de Lyon, Equipes 15 et 16, INSERM, Unité 1052, CNRS, UMR 5286, Lyon, France;

${ }^{10}$ Department of Infectious and Tropical Diseases, Saint-Antoine Hospital, AP-HP, Paris, France;

${ }^{11}$ Sorbonne Universités, UPMC Univ Paris 06, UMR_S 1136, Institut Pierre Louis d'Epidémiologie et de Santé Publique, Paris, France.

\section{Corresponding author:}


Anders Boyd, MPH, PhD

Service de maladies infectieuses - Hôpital Saint-Antoine

184 rue du Faubourg Saint-Antoine

75012 Paris - FRANCE

Tel: +33171970517

Fax: +33149282149

Email: anders.boyd@upmc.fr

Running head: Seroclearance \& HIV-HBV infection in SSA 


\section{ABSTRACT}

Background and aim: In Sub-Saharan Africa, seroclearance of hepatitis B surface antigen (HBsAg) and hepatitis B " $\mathrm{e}$ " antigen (HBeAg), including their quantifiable markers, have rarely been evaluated during long-term antiviral treatment among patients co-infected with HIV and hepatitis B virus (HBV).

Methods: In this prospective cohort study from two randomized-control trials in Côte d'Ivoire, 161 antiretroviral-naïve HIV-HBV co-infected patients starting lamivudine $(n=76)$ or tenofovir/emtricitabine $(n=85)$ containing antiretroviral therapy were included. HBV-DNA was quantified using an in-house assay (detection limit=12 copies $/ \mathrm{mL}$ ) and HBsAg quantification ( $\mathrm{qHBsAg}$ ) using the Elecsys assay.

Results: Overall, 33 (20.5\%) patients were HBeAg-positive, 121 (75.2\%) had detectable HBV-DNA and 92/93 (98.9\%) harbored HBV genotype E. Median treatment duration was 35.5 months (IQR: 24.3-36.4). Among HBeAg-positive patients, cumulative proportion with HBeAg-seroclearance was $46.3 \%(n=14)$. Overall, cumulative proportion of HBsAg-seroclearance was $6.6 \%(n=10)$. Lower baseline qHBsAg levels and strong 12-month declines in qHBsAg were significantly associated with HBsAg-seroclearance for both HBeAg-negative and positive patients. When taken at certain levels, these determinants provided moderate sensitivity (Se) and specificity $(\mathrm{Sp})$ in predicting HBsAg-seroclearance at month-36 ( $\leq 1000$ $\mathrm{IU} / \mathrm{mL}$ at baseline, $\mathrm{Se}=0.80, \mathrm{Sp}=0.80 ; \geq 1.0 \log _{10} \mathrm{IU} / \mathrm{mL}$ drop at month-12, Se=0.57, $\mathrm{Sp}=1.00$ ). Instead, qHBsAg levels $\leq 100$ or $\leq 10 \mathrm{IU} / \mathrm{mL}$ at month-12 were optimal (both $\mathrm{Se}=0.90, \mathrm{Sp}=1.00$ ). Detectable HBVDNA provided fairly high $\mathrm{Se}$ and $\mathrm{Sp}$ when evaluated at baseline $(\mathrm{Se}=1.00, \mathrm{Sp}=0.80)$, but not at month-12 $(\mathrm{Se}=0.80, \mathrm{Sp}=0.40)$.

Conclusions: HBsAg seroclearance rates are not common in patients from Sub-Saharan Africa treated with anti-HBV containing antiretroviral therapy. qHBsAg levels at twelve months of treatment may accurately predict HBsAg-seroclearance. 
Key words: HBsAg quantification; HBeAg quantification; immunosuppression; serological endpoints; chronic viral hepatitis. 


\section{INTRODUCTION}

In Sub-Saharan Africa (SSA), at most $10 \%$ of patients infected with the human immunodeficiency virus (HIV) are also chronically infected with hepatitis B virus (HBV). ${ }^{1}$ From studies in industrialized countries, co-infection is clearly associated with increased risk of liver cirrhosis, hepatocellular carcinoma, and liverrelated morbidity and mortality. ${ }^{2-4}$ Serum levels of HBV replication are strongly associated with these events ${ }^{5}$, while mounting evidence has shown a reduction of hepatocellular carcinoma in particular with antiviral-associated HBV suppression. ${ }^{6}$ Antiretroviral therapy (ART) with dual activity against HIV and HBV would then be considered ideal for co-infected patients in any setting.

Nevertheless, one of the most important surrogates in establishing therapeutic response is hepatitis B surface antigen ( $\mathrm{HBsAg})$, considering loss of $\mathrm{HBsAg}$ is strongly associated with reduced viral activity in the liver and improved clinical prognosis. ${ }^{7}$ HBsAg-loss has already been studied in HIV-HBV co-infected patients from industrialized countries treated with long-term tenofovir (TDF)-containing ART, with prospective results demonstrating cumulative HBsAg-seroclearance rates ranging from $5-8 \%{ }^{8,9}$ To date, the sparse literature on HBsAg-seroclearance in SSA includes only small numbers of patients and extends to roughly one year of follow-up. ${ }^{10,11}$ This period would be judged fairly inadequate, given that $\mathrm{HBsAg-}$ loss is most likely to occur within the first three years of treatment. ${ }^{9}$

The aim of the study herein is then to estimate the rates of $\mathrm{HBsAg}$-seroclearance and its determinants among HIV-HBV patients from Côte d'Ivoire initiating either a lamivudine (LAM) or TDF-containing ART regimen. Using hepatitis $B$ " $e$ " antigen ( $\mathrm{HBeAg}$ ) as another marker of clinical improvement, yet possibly less useful given the characteristically low proportion of patients with $\mathrm{HBeAg}$-positive serology on the continent $^{12}$, we further estimated rates of $\mathrm{HBeAg}$-seroclearance and its determinants among $\mathrm{HBeAg}$ - 
positive patients. Finally, we used biomarkers strongly correlated with these events, HBsAg quantification (qHBsAg) and $\mathrm{HBeAg}$ quantification (qHBeAg), in order to examine the on-treatment kinetics after ART-initiation and its ability to predict seroclearance.

\section{METHODS}

\section{Study population}

The VarBVA study ${ }^{13}$ is an observational cohort including patients from two prospective, randomized, open-label, multi-center trials in Abidjan, Côte d'Ivoire: Trivacan ANRS 1269 (NCT00158405), aimed at evaluating the benefits and risks of structured treatment interruption; and Temprano ANRS 12136 (NCT00495651), aimed at evaluating the benefits and risks of starting ART earlier than current World Health Organization (WHO) recommendations. Study randomization and follow-up procedures have been detailed elsewhere. ${ }^{14,15}$

Briefly, study inclusion criteria were as follows - both studies: age $\geq 18$ years, HIV-1 or mixed HIV-1/2 infection, and ART-naïve (with the exception of short-course treatment for the prevention of mother-tochild HIV transmission); Trivacan: CD4 cell count between $150-350 / \mathrm{mm}^{3}$ or CD4 percentage between 12.5\%-20.0\%; Temprano: CD4 cell count $<800 / \mathrm{mm}^{3}$ and no concurrent criteria for ART-initiation according to most recent WHO guidelines. The study non-inclusion criteria were as follows - both studies: residence outside of Abidjan; unwillingness to participate; pregnancy; severe renal or hepatic disease; severe psychiatric disorder; or any ongoing severe clinical features of undiagnosed origin; Trivacan: severe hematological disorder or Karnofsky score <50; Temprano: breastfeeding, ongoing 
tuberculosis disease, or severe cardiac disorder. All participants gave written informed consent and approval of the study protocols were obtained by the Ministry of Health of Côte d'Ivoire and the French National Agency for Research on AIDS and Viral Hepatitis (ANRS, Paris, France).

\section{Antiretroviral treatment}

In the Trivacan trial, all patients started ART at inclusion, receiving zidovudine/LAM in combination with either efavirenz or ritonavir-boosted lopinavir ("LAM-containing ART"). After a 6 to 18 months phase of continuous ART, those who fulfilled randomization criteria (CD4 $>350 / \mathrm{mm}^{3}$, plasma HIV-1 RNA $<300$ copies $/ \mathrm{mL}$ ) were randomized to one of three arms: continuous-ART, CD4-guided ART interruptions (reintroduction when CD4 $<250 / \mathrm{mm}^{3}$, interruption when CD4 $>350 / \mathrm{mm}^{3}$ ), or fixed-schedule ART interruptions (2-months-off and 4-months-on). Those who did not reach randomization criteria underwent continuous-ART. In the Temprano trial, patients were randomized at inclusion to either start ART immediately or defer ART until WHO ART-initiation criteria were met. In both strategies, the firstline ART regimen was TDF/FTC in combination with one other antiretroviral agent: efavirenz, zidovudine, or ritonavir-boosted lopinavir ("TDF/FTC-containing ART").

\section{Study visits}

For the VarBVA study, we considered all patients included in the Trivacan trial between December 2002 and April 2004 and all patients included in the Temprano trial between March 2008 and March 2011. All patients from these studies were tested for HBsAg at study inclusion (Mini Vidas ${ }^{\circledR}$ assay; Biomerieux, Marcy l'Etoile, France). We included patients who tested HBsAg-positive, confirmed by the HBsAg Qual II Architect assay (Abbott Laboratories, Rungis, France), and who started ART at inclusion or any time 
during participation in the trial. For this analysis, we define the "baseline" visit at ART-initiation and "follow-up" visits at each yearly visit thereafter until the date of last follow-up (with available frozen sample), study termination, permanent treatment discontinuation, or treatment switch. In the Temprano study, if the last follow-up visit was not on the yearly interval, the closest 6-month visit was used instead.

Plasma alanine aminotransferase (ALT) at baseline and aspartate aminotransferase (AST) at baseline and during follow-up were quantified during the Trivacan study, while ALT was available at for all visits during the Temprano study. CD4+ cell counts (True Count technique on FACScan, Becton Dickinson, AalstEnembobegem, Belgium) and plasma HIV-1 RNA [real-time polymerase chain reaction (PCR) on TaqMan technology ABI Prism 7000, Applied Biosystems, Courtaboeuf, France; detection threshold: 300 copies/mL] were measured at baseline and every follow-up visit. ${ }^{16}$

\section{HBV viral loads and serological battery}

From frozen samples stored at $-80^{\circ} \mathrm{C}, \mathrm{HBV}$-DNA viral loads were quantified at baseline and every followup visit using an in-house PCR-based assay (QuantiFast SYBR ${ }^{\circledR}$ Green PCR kit, Qiagen, Courtaboeuf, France; Light Cycler 480, Roche, Boulogne-Billancourt, France) with a detection limit of $12 \mathrm{copies} / \mathrm{mL}^{13}$

Qualitative HBsAg was detected using the HBsAg Qual II test (detection limit=0.03 IU/mL, Architect, Abbott Laboratories, Rungis, France) at baseline and during follow-up. Qualitative HBeAg and anti-HBe antibodies (anti-HBeAb) were detected using the Elecsys assay (Roche Diagnostics, Meylan, France) for the same visits. The following definitions were used throughout the study: HBeAg-seroclearance, $\mathrm{HBeAg-loss}$ from the previous visit, and $\mathrm{HBsAg}$-seroclearance, $\mathrm{HBsAg}$-loss from the previous visit. 


\section{Quantification of HBV serological markers}

For HBsAg-positive samples, qHBsAg was quantified using the Elecsys assay with the Modular E170 analyzer (Roche Diagnostics, Meylan, France). Similarly for HBeAg-positive samples, qHBeAg was quantified using the Elecsys assay. This automated electrochemiluminescence immunoassay gives qHBeAg levels in a semi-quantitative manner and is interpreted as the ratio of sample relative light units to a cut-off value. These units were converted to Paul Ehrlich Institute units (PEIU/mL) from a previously established protocol. ${ }^{17}$

\section{Statistical analysis}

Statistical analysis was performed using STATA (v12.1, College Station, TX) and significance was determined using a $p$-value $<0.05$. Unless otherwise specified, all comparisons were performed using Kruskal-Wallis test for continuous variables and Pearson $\chi^{2}$ test or Fisher's exact test for categorical variables.

In HBeAg-positive patients, median (IQR) qHBeAg levels and change in qHBeAg from baseline $(\triangle \mathrm{qHBeAg})$ were summarized at each yearly interval. For all patients, median (IQR) qHBsAg levels and change in qHBsAg from baseline ( $\triangle \mathrm{qHBsAg}$ ) were also summarized at each yearly interval, but due to substantial differences in qHBsAg kinetics, patients were stratified by HBeAg-status at baseline. ${ }^{8,18}$ Preliminary analysis (Supplementary results) demonstrated no significant differences between patients undergoing LAM versus TDF/FTC-containing ART and hence they were pooled together. 
Determinants of qHBsAg levels per HBeAg-status were evaluated over time with a Generalized Estimating Equation, accounting for within-patient effects using an unstructured working correlation. A multivariable model was constructed by adding all covariables with a $p<0.1$ in univariable analysis and removing those variables above this $p$-value threshold in backwards-stepwise fashion. In post hoc analysis, we compared $\triangle \mathrm{qHBsAg}$ during follow-up between the following factors by including an interval timexrisk-factor interaction term in the multivariable model: TDF/FTC- versus LAM-containing ART and LAM-randomization arm.

Finally, several clinical factors were compared between patients who did versus did not achieve specific serological endpoints. In exploratory analysis, we selected several criteria a priori to predict HBsAgseroclearance: $\mathrm{qHBsAg} \leq 10,000 \mathrm{IU} / \mathrm{mL}, \leq 1000 \mathrm{IU} / \mathrm{mL}$, and $\leq 100 \mathrm{IU} / \mathrm{mL}$ at baseline; $\mathrm{qHBsAg} \leq 100 \mathrm{IU} / \mathrm{mL}$ and $\leq 10 \mathrm{IU} / \mathrm{mL}$ at month-12; qHBsAg drop $\geq 1.0$ and $\geq 2.0 \log _{10} \mathrm{IU} / \mathrm{mL}$ at month-12; and HBV-DNA >12 copies/mL at baseline and at month-12. Time-dependent classification probabilities, sensitivity (Se) and specificity (Sp), and predictive values, positive predictive value (PPV) and negative predictive value (NPV), were calculated for each criterion as a predictor of HBsAg-loss until months- 24 and 36 . Time-dependent receiver operator characteristic (ROC) curves were constructed and area under the ROC curves (AUC) were compared between criteria using the method of Blanch et al. ${ }^{19}$ Likewise, we also examined prediction of HBsAg-seroclearance with two commonly obtained markers: HBeAg-serology at baseline and change in CD4+ cell counts at 12-months. In order to determine whether adding these criteria improved prediction of $\mathrm{HBsAg}$-seroclearance, $\mathrm{HBeAg}$-serology and 12-month change in $\mathrm{CD} 4+$ cell counts were combined with the optimal qHBsAg criterion using the "or" Boolean operator and AUCs were compared to the optimal qHBsAg criterion alone. Due to the low prevalence of HBeAg-positive status, we did not attempt similar analysis for HBeAg-seroclearance. 


\section{RESULTS}

\section{Description of the study population}

At inclusion, 259 of 2465 patients enrolled in both trials were HBsAg-positive. Among them, 98 were not included in analysis because they did not have confirmed HBsAg-positive serology $(n=31)$ or had suspected acute HBV-infection ( $n=1)$, never initiated ART ( $n=30)$, had only one follow-up visit $(n=16)$, discontinued ART $<6$ months due to pregnancy $(n=3)$ or adverse event $(n=2)$, had missing data on HBV viral load at baseline $(n=8)$, or had missing data on qHBsAg levels at baseline or during follow-up ( $n=7)$. In total, 161 patients were included with 76 and 85 undergoing LAM- and TDF/FTC-containing ART, respectively. Among those undergoing LAM-containing ART, 12 (15.8\%) were randomized to continuousART, 22 (29.0\%) to CD4-guided ART interruptions, 28 (36.8\%) to fixed-schedule ART interruptions, and 14 (18.4\%) non-randomized while taking continuous LAM.

A total of 33 (20.5\%) patients were HBeAg-positive. Demographic, HIV and HBV-related characteristics at baseline are summarized in Table 1 and stratified by HBeAg-status. As expected, patients with HBeAgpositive serology were more likely to have detectable HBV-DNA $(p<0.001)$ and higher HBV-DNA viral loads ( $p=0.0001$ ). HBeAg-positive patients were also more severely immunocomprimised, as they had significantly lower CD4+ cell counts $(p=0.02)$ and higher WHO clinical stages of HIV-infection $(p=0.01)$ when compared to HBeAg-negative patients (Table 1).

Patients were followed for a median 35.5 months (IQR: 24.3-36.4). In patients with detectable HBV-DNA at baseline, undetectable HBV-DNA was achieved by $97 / 121$ (cumulative rate $=83.0 \%$ ) at the end of 
follow-up, while HBeAg-positive patients had a lower cumulative rate of undetectable HBV-DNA compared to $\mathrm{HBeAg-negative} \mathrm{patients} \mathrm{(58.8 \%} \mathrm{versus} 91.1 \%$, log-rank test $p=0.0002$ ).

\section{HBeAg quantification during treatment}

In the $33 \mathrm{HBeAg-positive} \mathrm{patients,} \mathrm{overall} \mathrm{median} \mathrm{qHBeAg} \mathrm{was} 173.1 \mathrm{PEIU} / \mathrm{mL}$ (IQR: 85.8-367.0) at baseline. qHBeAg levels and $\triangle \mathrm{qHBeAg}$ are summarized for each follow-up time point in Figure $1 \mathrm{~A}$. There was a progressive drop in qHBeAg levels, reaching low levels for the majority of patients.

\section{Rates and determinants of $\mathrm{HBeAg}$-seroclearance}

A total of $14 / 33$ patients (42.4\%) had HBeAg-serocleance after a median 14.8 months (IQR: 11.2-25.2) of anti-HBV-containing ART, giving an incidence rate of 1.7/100 person-years and cumulative proportion of HBeAg-seroclearance at $46.3 \%$ (Figure 2A). Comparison of clinical, virological, and immunological factors between patients with versus without $\mathrm{HBeAg}$-seroclearance are summarized in Table 2. Lower baseline qHBsAg $(p=0.02)$ and greater decreases of 12 -month $\triangle \mathrm{qHBsAg}(p=0.002)$ were significantly associated with HBeAg-seroclearance. When examining the qHBeAg profiles of patients with HBeAg-seroclearance (Figure 2A), it would appear that most patients had relatively low qHBeAg at baseline, with three patients exhibiting severe declines in qHBeAg after ART-initiation.

\section{HBsAg quantification during treatment}

Overall, median qHBsAg levels were $3.99 \log _{10}$ IU/mL (IQR: 3.37-4.22) at baseline, with significantly higher qHBsAg-levels among patients with HBeAg-positive (4.61 IU/mL, IQR: 4.24-4.91) versus HBeAg- 
negative serology (3.82 IU/mL, IQR: 3.27-4.10) ( $p=0.0001)$. qHBsAg levels and $\triangle \mathrm{qHBsAg}$ for each followup time point are summarized in Figure $1 \mathrm{~B}$ among $\mathrm{HBeAg}$-positive and $\mathrm{HBeAg}$-negative patients. A large reduction in qHBsAg was observed after ART-initiation for mainly HBeAg-positive patients.

In multivariable analysis (Supplementary Table 1), baseline qHBsAg level emerged as a significant predictor of qHBsAg levels for all time-points (HBeAg-positive, $p<0.001$ and HBeAg-negative, $p<0.001$ ). Significant declines from baseline were observed for both HBeAg-positive and HBeAg-negative patients. In post hoc analysis, there was no significant difference in $\triangle \mathrm{qHBsAg}$ during follow-up between LAMversus TDF/FTC-containing ART (HBeAg-positive, $p=0.2 ; \mathrm{HBeAg-negative,} p=0.3$ ). Significant differences in $\triangle \mathrm{qHBsAg}$ between LAM-randomization groups were observed among HBeAg-negative $(p=0.0007)$ and not HBeAg-positive patients $(p=0.17)$. In further analysis, there was an immediate mean difference of $0.21 \log _{10} / \mathrm{mL}$ of $\triangle \mathrm{qHBsAg}$ in HBeAg-negative patients randomized to continuous LAM during the first 12 months compared to those randomized to receive treatment interruptions, which was maintained throughout follow-up $(p=0.004)$.

\section{Rates and determinants of HBsAg-seroclearance}

A total of 10/161 patients (6.2\%) had HBsAg-seroclearance after a median 12.3 months (IQR: 12.2-23.5) from ART-initiation, of whom 5/33 (cumulative proportion=15.8\%) were $\mathrm{HBeAg}$-positive and 5/128 (cumulative proportion=4.2\%) HBeAg-negative (log-rank test $p=0.02$ ). In HBeAg-positive patients, lower HBV-DNA viral loads, lower baseline qHBsAg levels, greater 12-month changes in CD4+ cell count and qHBsAg were all significantly associated with HBsAg-seroclearance (Table 3). In HBeAg-negative patients, lower baseline qHBsAg levels and greater 12-month changes in HBV-DNA and qHBsAg were significantly associated with HBsAg-seroclearance (Table 3). As shown in Figure 2B, patients with HBsAg- 
seroclearance either had fairly low baseline qHBsAg levels or had steep declines in qHBsAg after ARTinitiation. Interestingly, one $\mathrm{HBeAg}$-positive patient with $\mathrm{HBsAg}$-seroclearance exhibited rather slow declines in qHBsAg during the first 12-months, which followed in a rapid decline at the next study visit.

\section{Serological quantifiable markers as predictors of HBsAg-seroclearance}

Time-dependent classification probabilities and predictive values of HBsAg-seroclearance are given in Table 4 for a variety of virological and serological criteria. Detectable HBV-DNA at baseline provided perfect Se and NPV during follow-up, yet PPV was rather poor. Baseline $\mathrm{qHBsAg}$ levels at $\leq 1000 \mathrm{IU} / \mathrm{mL}$ were ideal for predicting HBsAg-loss at both month-24 and month-36 of anti-HBV containing ART. During treatment, 12-month changes in qHBsAg greater than 1.0 or $2.0 \log _{10} \mathrm{IU} / \mathrm{mL}$ had excellent Sp, albeit with very poor Se. Nevertheless, the optimal markers in predicting HBsAg-loss at month-36 were HBsAg levels $\leq 100$ and $\leq 10 \mathrm{IU} / \mathrm{mL}$ at month-12 of treatment.

Accordingly, AUCs at month-36 were significantly higher for qHBsAg levels $\leq 100$ and $\leq 10 \mathrm{lU} / \mathrm{mL}$ at month-12 of treatment when compared to all other criteria $(p<0.04)$, except for baseline $q H B s A g \leq 1000$ $\mathrm{IU} / \mathrm{mL}$ ( $p=0.14$ and 0.14 , respectively) and detectable HBV-DNA at baseline ( $p=0.6$ and 0.6 , respectively). The only other significant difference in AUC at month-36 was observed between baseline qHBsAg $\leq 1000$ $\mathrm{IU} / \mathrm{mL}$ and detectable HBV-DNA at month-12 of treatment $(p<0.001)$. Of note, adding detectable HBVDNA at baseline and qHBsAg levels $\leq 100 \mathrm{IU} / \mathrm{mL}$ at month-12 together did not improve prediction ( $p=0.9$ ).

When examining routinely collected parameters, time-dependent classification probabilities were substantially lower for both HBeAg-positive serology and 12-month change in CD4+ cell count $>200 / \mathrm{mm}^{3}$ compared to qHBsAg levels $\leq 100 \mathrm{IU} / \mathrm{mL}$ at month-12 (Table 4), with significantly lower AUCs at month-36 
(respectively 0.636 and 0.642 versus $0.948, p=0.03$ and $p=0.03$ ). Even after adding these markers to qHBsAg levels $\leq 100 \mathrm{IU} / \mathrm{mL}$ at month-12, there was no significant gain in AUC at month-36 (for HBeAgpositive serology: $0.900, p=0.6$; for 12 -month change in CD4+ cell count $>200 / \mathrm{mm}^{3}, 0.690, p=0.001$ ).

\section{DISCUSSION}

In our study, we present the longest, prospective follow-up to date of serological outcomes among treated HIV-HBV co-infected patients in SSA. In HBeAg-positive patients, HBeAg-seroclearance was achieved in a cumulative $46.3 \%$ and $\mathrm{HBsAg}$-seroclearance in a cumulative $15.8 \%$. In HBeAg-negative patients, cumulative HBsAg-seroclearance was observed in $4.2 \%$ at the end of follow-up. Despite the high prevalence of $\mathrm{HBV}$ genotype $\mathrm{E}$, which is known to have markedly slower kinetics of HBsAg decline during NA-therapy ${ }^{20}$, these rates fell surprisingly close in line with previous studies among co-infected patients harboring non-E genotypes. ${ }^{8,18,21-23}$ Importantly, the only two determinants consistent in predicting both $\mathrm{HBeAg}$ and $\mathrm{HBsAg}$-seroclearance were lower qHBsAg levels at baseline and stronger decreases in qHBsAg kinetics during the first 12-months after initiating treatment. In HBeAg-positive patients, neither qHBeAg at baseline nor its 12-month change was able to accurately predict any seroclearance event, questioning the clinical utility of this particular marker.

Indeed, the use of qHBsAg has gained a great deal of attention as an indicator for HBsAg-seroclearance events during treatment ${ }^{24}$, yet has been found to be fairly elusive for nucleoside/nucleotide analogue (NA)-based therapy. ${ }^{25}$ In co-infected patients treated with potent NAs possessing anti-HBV activity, low levels of pre-treatment qHBsAg have been suggested as an adequate predictor of $\mathrm{HBsAg}$ -

seroclearance. ${ }^{18,22}$ Large declines of qHBsAg in the order of $2 \log _{10} \mathrm{IU} / \mathrm{mL}$ has also provided a rather 
accurate measure of HBsAg-loss in treated HIV-HBV co-infected patients ${ }^{8,21}$; however, this might not occur within the first year of treatment. ${ }^{9}$ In our study, we observed that a lower qHBsAg level at 12months of anti-HBV containing ART was an ideal predictor of HBsAg-seroclearance, giving both high sensitivity and specificity and significantly higher AUC compared to almost all other criteria. This criterion would appear to accommodate profiles of patients with either low baseline qHBsAg or large 12month declines in qHBsAg who would be likely to lose HBsAg-positive serology. Of course, these findings would need to be confirmed for larger cohorts with more seroclearance events.

The difficulty in defining milestones for qHBsAg is extremely important to consider if it is to be used in resource-limited settings. One alternative marker of choice would certainly be HBV-DNA, allowing assessment of treatment efficacy in suppressing virus and providing a potential explanation of viralinduced liver pathology. However, viral load quantification runs at almost a 6-times higher cost than serological assays. In addition, as access to anti-HBV treatments without any evidence of resistance mutations, namely $\operatorname{TDF}^{26}$, increases on the continent ${ }^{27}$, the need to assess virological breakthrough becomes less warranted. While although we observed that detectable HBV-DNA provided high sensitivity and specificity in our study, it has been repeatedly observed to be a poor predictor of serological events..$^{8,9,18}$

Intriguingly, there was no recognizable difference in qHBsAg decline between specific anti-HBV NAs included in the ART regimen for either HBeAg-positive or HBeAg-negative patients. In HBeAg-positive patients, only one head-to-head comparison between LAM and TDF during the first 48 weeks has been performed with respect to on-treatment kinetics of qHBsAg, demonstrating no significant differences in qHBsAg decline. ${ }^{21}$ This observation could be linked to HBV-DNA replication, which is known to be more strongly correlated with qHBsAg levels during HBeAg-positive chronic infection. ${ }^{28,29}$ HBV-DNA replication 
in HBeAg-positive patients from both our study and others substantially declined during the first twelve months of therapy with no significant difference between anti-HBV treatment regimens. The similar initial kinetics of HBV-DNA replication would likely follow that of qHBsAg. In HBeAg-negative HBVmonoinfected patients, larger decreases in qHBsAg levels have been observed with TDF compared to other NAs, especially LAM. ${ }^{30}$ Of course, the large difference regarding our study was the overwhelming majority of patients with HBV genotype $E$, in whom very slow declines in qHBsAg during potent NAtreated HBeAg-negative infection have been observed compared to non-E genotypes. ${ }^{20}$

Since the study population herein was HIV-HBV co-infected, there are inherent differences when comparing our results to HBV-monoinfected patients. More recent research directly comparing HIV-HBV and HBV-monoinfected patients, treated specifically with TDF and recruited in the same catchment areas, has actually observed no difference in infection groups with regards to HBeAg-seroclearance, HBeAg-seroconversion, or HBsAg-seroclearance. ${ }^{31,32}$ However, one more discernable feature that could drive differences in seroclearance rates is HIV-associated immunosuppression.

Nonetheless, immune function has been inconsistently shown to play a role in seroclearance. We have previously demonstrated that baseline CD4 cell count $>350 / \mathrm{mm}^{3}$ is associated with faster $\mathrm{qHBsAg}$ declines in TDF-treated co-infected patients. ${ }^{18}$ Yet since the population of this study had extensive treatment experience prior to TDF-initiation, those with CD4+ cell counts $<350 / \mathrm{mm}^{3}$ may have represented a specific subgroup with impaired capacity to produce effective immunity. ${ }^{33}$ Others have found strong correlations with increases in CD4+ cell count and early kinetics of $\mathrm{qHBsAg}^{8}$, while higher degrees of immunosuppression have been associated with seroclearance in general. ${ }^{34}$ Broadening these results, we observed that 12 -month changes in CD4+ cell count were significantly associated with $\mathrm{HBsAg}$ seroclearance, but only in HBeAg-positive patients. Since the development of anti-HBV immunity is quite 
active during $\mathrm{HBeAg}$-positive infection ${ }^{7}$, perhaps the additive effect of immunorestoration facilitates HBsAg-seroclearance mainly in the HBeAg-positive phase.

Our study does have a certain number of limitations to address. First, we have stratified LAM- and TDF/FTC-containing ART in past analyses due to the important differences in study designs, while avoiding any comparisons between treatment groups. ${ }^{13}$ Patients undergoing LAM-containing ART had much lower CD4+ cell counts and the majority was undergoing treatment interruptions during therapy. However, almost all CD4+ cell counts were at levels that have not been associated with differences in qHBsAg/qHBeAg (i.e. $>350$ cells $/ \mathrm{mm}^{3}$ ) and qHBsAg levels are generally known to remain stable during bouts of HBV-DNA replication ${ }^{29,35}$, which might have occurred during treatment interruption. ${ }^{36}$ Second, there were only a handful of HBeAg-seroclearance events and even fewer numbers of patients with HBsAg-seroclearance. Consequently, we did not have sufficient power to perform multivariable analysis and determine independent factors associated with these events, while classification probabilities and predictive values for HBsAg-seroclearance need to be interpreted with some caution. Finally, patients with severe liver-related morbidity were excluded from both trials, thus partially limiting the generalizability of our results.

In conclusion, seroclearance rates in treated HIV-HBV co-infected patients in SSA, harboring predominately HBV genotype $\mathrm{E}$, are greatly similar to previous studies in industrialized countries. On the whole, our data underscore the difficulty in achieving these therapeutic endpoints, while the slow declines in HBsAg quantification draws further attention to the persistent nature of chronic hepatitis B. The low rates of serological responses in HIV-HBV co-infected patients stress the need for life-long ART containing an anti-HBV agent, which is an important consideration for scale-up programs in SSA. 


\section{ACKNOWLEDGEMENTS}

We thank all patients who participated in both trials. We also gratefully acknowledge the valuable contributions of the SMIT, CeDReS, CEPREF, USAC, CIRBA, CNTS, La Pierre Angulaire, Hôpital Général Abobo, Formation Sanitaire Anonkoua Kouté, Centre de santé El Rapha, the Programme PACCI team, as well as the INSERM exU593 and U897 teams (Abanou Matthieu, Adou Isabelle, Aman Adou, Anasthasie Yapo, Bakayoko Ibouraîma, Bombo Léontine, Célestin N'chot, Christian Kouadio, Cissé Edwidge, Coulibaly Ali, Djédjé Lucien, Djetouan Hugues, Djobi-Djo Edouard, Goly Jocelyn, Kassi Marie-Cécile, Koffi Justine, Koffi-N’Dri Aholi, Konan Sylvie, Konaté Mamadou, Kouadio Bertin, Kouamé Martin, Kouadio Cheftin, Kouadio Martin, Kouadio Victoire, Kouakou-Aboua Adrienne, Kouakou Yao, Kouamé Antoine, Kouamé Ferdinand, Kouamé Gérald, Kouamé Justine, Labibi Georgette, Lehou Jean, Lokou Benjamin, Martin Marie-Pierre, Moh Jules, Moussa-Doumbia Mariam, N’Chot Célestin, N’Dri Marie Julie, Nalourgou Tuo, N'Goran Brou, Nogbout Marie-Pascale, Orne-Gliemann Joanna, Ouattara Bakary, Ouattara Minata, Oupoh Joséphine, Sidibé Abdelh, Siloué Bertine, Soro Adidiata, Tchehy Amah-Cécile, Yao Emile, Yao Juliette, Yoro Guei, and Zaho Marcel); and Bristol-Myers Squibb for providing Zerit and Videx; Gilead Sciences, for the donation of Truvada; and Merck Sharp \& Dohme, for the donation of Stocrin. We would finally like to thank Paul Dény and Mariama Issoufou for the quantification of HBV-DNA viral loads and HBV sequencing as well as Gilles Peytavin for determining antiviral concentrations.

This study was supported by funds from the Agence Nationale de Recherche sur le Sida et les Hépatites (ANRS 12240). The Trivacan and Temprano studies also received funding from the ANRS (ANRS 1269/ANRS 12104 and ANRS 12136, respectively). Finally, A.B. was awarded a post-doctoral fellowship from the ANRS and SIDACTION for some of the work presented in this manuscript. 


\section{Potential conflicts of interest}

The authors report no conflicts of interest relative to the article.

\section{REFERENCES}

1. Lacombe K, Rockstroh J. HIV and viral hepatitis coinfections: advances and challenges. Gut. 2012 May;61 Suppl 1:i47-58.

2. Ioannou GN, Bryson CL, Weiss NS, Miller R, Scott JD, Boyko EJ. The prevalence of cirrhosis and hepatocellular carcinoma in patients with human immunodeficiency virus infection. Hepatol. 2013 Jan;57(1):249-57.

3. Falade-Nwulia O, Seaberg EC, Rinaldo CR, Badri S, Witt M, Thio CL. Comparative risk of liver-related mortality from chronic hepatitis B versus chronic hepatitis C virus infection. Clin Infect Dis. 2012 Aug;55(4):507-13.

4. Ly KN, Xing J, Klevens RM, Jiles RB, Ward JW, Holmberg SD. The increasing burden of mortality from viral hepatitis in the United States between 1999 and 2007. Ann Intern Med. 2012 Feb 21;156(4):271-8.

5. Chen C-J, Yang H-I, lloeje UH, REVEAL-HBV Study Group. Hepatitis B virus DNA levels and outcomes in chronic hepatitis B. Hepatol. 2009 May;49(5 Suppl):S72-84.

6. Papatheodoridis GV, Chan HL-Y, Hansen BE, Janssen HLA, Lampertico P. Risk of hepatocellular carcinoma in chronic hepatitis B: Assessment and modification with current antiviral therapy. J Hepatol. 2015 Apr;62(4):956-67. 
7. European Association For The Study Of The Liver. EASL clinical practice guidelines: Management of chronic hepatitis B virus infection. J Hepatol. 2012 Jul;57(1):167-85.

8. Zoutendijk R, Zaaijer HL, de Vries-Sluijs TEMS, Reijnders JGP, Mulder JW, Kroon FP, et al. Hepatitis B surface antigen declines and clearance during long-term tenofovir therapy in patients coinfected with HBV and HIV. J Infect Dis. 2012 Sep 15;206(6):974-80.

9. Boyd A, Maylin S, Gozlan J, Delaugerre C, Simon F, Girard P-M, et al. Use of hepatitis B surface and " $\mathrm{e}$ " antigen quantification during extensive treatment with tenofovir in patients co-infected with HIV-HBV. Liver Int. 2015 Mar;35(3):795-804.

10. Hamers RL, Zaaijer HL, Wallis CL, Siwale M, Ive P, Botes ME, et al. HIV-HBV Coinfection in Southern Africa and the Effect of Lamivudine- Versus Tenofovir-Containing CART on HBV Outcomes. J Acquir Immune Defic Syndr. 2013 Oct 1;64(2):174-82.

11. Matthews GV, Manzini P, Hu Z, Khabo P, Maja P, Matchaba G, et al. Impact of lamivudine on HIV and hepatitis B virus-related outcomes in HIV/hepatitis B virus individuals in a randomized clinical trial of antiretroviral therapy in southern Africa. AIDS. 2011 Sep 10;25(14):1727-35.

12. Hadziyannis SJ. Natural history of chronic hepatitis B in Euro-Mediterranean and African countries. J Hepatol. 2011 Jul;55(1):183-91.

13. Boyd A, Moh R, Gabillard D, le Carrou J, Danel C, Anglaret X, et al. Low risk of lamivudine-resistant hepatitis B virus and hepatic flares in treated HIV-HBV co-infected patients from Côte d'Ivoire. Antivir Ther. 2015 (in press)

14. Danel C, Moh R, Minga A, Anzian A, Ba-Gomis O, Kanga C, et al. CD4-guided structured antiretroviral treatment interruption strategy in HIV-infected adults in west Africa (Trivacan ANRS 1269 trial): a randomised trial. Lancet. 2006 Jun 17;367(9527):1981-9. 
15. Jean K, Gabillard D, Moh R, Danel C, Fassassi R, Desgrées-du-Loû A, et al. Effect of early antiretroviral therapy on sexual behaviors and HIV-1 transmission risk among adults with diverse heterosexual partnership statuses in Côte d'Ivoire. J Infect Dis. 2014 Feb 1;209(3):431-40.

16. Rouet F, Ekouevi DK, Chaix M-L, Burgard M, Inwoley A, Tony TD, et al. Transfer and evaluation of an automated, low-cost real-time reverse transcription-PCR test for diagnosis and monitoring of human immunodeficiency virus type 1 infection in a West African resource-limited setting. J Clin Microbiol. 2005 Jun;43(6):2709-17.

17. Maylin S, Boyd A, Martinot-Peignoux M, Delaugerre C, Bagnard G, Lapalus M, et al. Quantification of hepatitis B e antigen between Elecsys HBeAg and Architect HBeAg assays among patients infected with hepatitis B virus. J Clin Virol. 2013 Apr;56(4):306-11.

18. Maylin S, Boyd A, Lavocat F, Gozlan J, Lascoux-Combe C, Miailhes P, et al. Kinetics of hepatitis B surface and envelope antigen and prediction of treatment response to tenofovir in antiretroviralexperienced HIV-hepatitis B virus-infected patients. AIDS. 2012 May 15;26(8):939-49.

19. Blanche P, Dartigues JF, Jacqmin-Gadda H. Estimating and comparing time-dependent areas under receiver operating characteristic curves for censored event times with competing risks. Stat Med. 2013;32(20):5381-97.

20. Boglione L, Cardellino CS, De Nicolò A, Cariti G, Di Perri G, D’Avolio A. Different HBsAg decline after 3 years of therapy with entecavir in patients affected by chronic hepatitis B HBeAg-negative and genotype A, D and E. J Med Virol. 2014 Nov;86(11):1845-50.

21. Matthews GV, Ali RJ, Avihingsanon A, Amin J, Hammond R, Bowden S, et al. Quantitative HBsAg and HBeAg predict hepatitis B seroconversion after initiation of HAART in HIV-HBV coinfected individuals. PLoS One. 2013;8(4):e61297. 
22. StrassI R, Reiberger T, Honsig C, Payer BA, Mandorfer M, Grabmeier-Pfistershammer K, et al. Viral determinants predicting hepatitis B surface antigen (HBsAg) seroclearance in HIV-/HBV-coinfected patients. J Viral Hepat. 2014 Jul;21(7):508-16.

23. Kosi L, Reiberger T, Payer BA, Grabmeier-Pfistershammer K, Strassl R, Rieger A, et al. Five-year ontreatment efficacy of lamivudine-, tenofovir- and tenofovir + emtricitabine-based HAART in HBVHIV-coinfected patients. J Viral Hepat. 2012 Nov;19(11):801-10.

24. Chan HL-Y, Thompson A, Martinot-Peignoux M, Piratvisuth T, Cornberg M, Brunetto MR, et al. Hepatitis B surface antigen quantification: why and how to use it in 2011 - a core group report. J Hepatol. 2011 Nov;55(5):1121-31.

25. Janssen HLA, Sonneveld MJ, Brunetto MR. Quantification of serum hepatitis B surface antigen: is it useful for the management of chronic hepatitis B? Gut. 2012 May;61(5):641-5.

26. Kitrinos KM, Corsa A, Liu Y, Flaherty J, Snow-Lampart A, Marcellin P, et al. No detectable resistance to tenofovir disoproxil fumarate after 6 years of therapy in patients with chronic hepatitis $B$. Hepatol. 2014 Feb;59(2):434-42.

27. Lemoine M, Eholié S, Lacombe K. Reducing the neglected burden of viral hepatitis in Africa: strategies for a global approach. J Hepatol. 2015 Feb;62(2):469-76.

28. Thompson AJV, Nguyen T, Iser D, Ayres A, Jackson K, Littlejohn M, et al. Serum hepatitis B surface antigen and hepatitis B e antigen titers: disease phase influences correlation with viral load and intrahepatic hepatitis B virus markers. Hepatol. 2010 Jun;51(6):1933-44.

29. Martinot-Peignoux M, Lapalus M, Asselah T, Marcellin P. The role of HBsAg quantification for monitoring natural history and treatment outcome. Liver Int. 2013 Feb;33 Suppl 1:125-32.

30. Boglione L, D'Avolio A, Cariti G, Gregori G, Burdino E, Baietto L, et al. Kinetics and prediction of HBsAg loss during therapy with analogues in patients affected by chronic hepatitis B $\mathrm{HBeAg}$ negative and genotype D. Liver Int. 2013 Apr;33(4):580-5. 
31. Plaza Z, Aguilera A, Mena A, Vispo E, Sierra-Enguita R, Tomé S, et al. Influence of HIV infection on response to tenofovir in patients with chronic hepatitis B. AIDS. 2013 Sep 10;27(14):2219-24.

32. Piroth L, Pol S, Lacombe K, Miailhes P, Rami A, Rey D, et al. Management and treatment of chronic hepatitis B virus infection in HIV positive and negative patients: the EPIB 2008 study. J Hepatol. 2010 Dec;53(6):1006-12.

33. Sauce D, Larsen M, Fastenackels S, Pauchard M, Ait-Mohand H, Schneider L, et al. HIV disease progression despite suppression of viral replication is associated with exhaustion of lymphopoiesis. Blood. 2011 May 12;117(19):5142-51.

34. Miailhes $P$, Trabaud $M-A$, Pradat $P$, Lebouché $B$, Chevallier $M$, Chevallier $P$, et al. Impact of highly active antiretroviral therapy (HAART) on the natural history of hepatitis B virus (HBV) and HIV coinfection: relationship between prolonged efficacy of HAART and HBV surface and early antigen seroconversion. Clin Infect Dis. 2007 Sep 1;45(5):624-32.

35. Boyd A, Gozlan J, Maylin S, Delaugerre C, Peytavin G, Girard P-M, et al. Persistent viremia in human immunodeficiency virus/hepatitis B coinfected patients undergoing long-term tenofovir: virological and clinical implications. Hepatol. 2014 Aug;60(2):497-507.

36. Dore GJ, Soriano V, Rockstroh J, Kupfer B, Tedaldi E, Peters L, et al. Frequent hepatitis B virus rebound among HIV-hepatitis B virus-coinfected patients following antiretroviral therapy interruption. AIDS. 2010 Mar 27;24(6):857-65. 


\section{FIGURE LEGENDS}

Figure 1. Decline in quantification of hepatitis B "e" antigen (qHBeAg) and hepatitis B surface antigen (qHBsAg) during treatment

For both qHBeAg, among HBeAg-positive patients (A), and qHBsAg (B), median levels and their IQRs (in bars) during follow-up are given on the left panels, while median changes from baseline and their IQRs (in bars) are given on the right panels. For qHBsAg levels, patients were stratified on baseline $\mathrm{HBeAg}$ status.

Figure 2. Rates of hepatitis B " $\mathrm{e}$ " antigen ( $\mathrm{HBeAg}$ ) and hepatitis B surface antigen (HBsAg) seroclearance during treatment

Cumulative proportions of $\mathrm{HBeAg}$-seroclearance, among $\mathrm{HBeAg}$-positive patients (A), and HBsAgseroclearance (B) are given in the left panel. For each patient achieving their respective endpoint, $\mathrm{HBeAg}$ quantification (qHBeAg) (A) or HBsAg quantification (qHBsAg) (B) during treatment is detailed on the right panel. For qHBsAg levels, patients were stratified on baseline HBeAg status. 


\section{TABLES}

Table 1. Baseline description of the study population stratified by HBeAg-status

\begin{tabular}{|c|c|c|c|c|}
\hline & $\begin{array}{c}\text { Total } \\
(n=161)\end{array}$ & $\begin{array}{l}\text { HBeAg-negative } \\
\qquad(n=128)\end{array}$ & $\begin{array}{c}\text { HBeAg-positive } \\
\quad(n=33)\end{array}$ & $p^{+}$ \\
\hline \multicolumn{5}{|l|}{ Demographic characteristics } \\
\hline Gender, male/female (\% males) & $54 / 107$ (33.5) & $46 / 82(35.9)$ & $8 / 25(24.2)$ & 0.2 \\
\hline Age, years* & $35(30-41)$ & $35(30-41)$ & $34(29-37)$ & 0.3 \\
\hline BMI, $\mathrm{kg} / \mathrm{m}^{2 *}$ & $21.5(19.3-24.2)$ & $21.9(19.4-24.9)$ & $21.1(19.1-22.3)$ & 0.06 \\
\hline Current smoker** & $17(10.7)$ & $13(10.3)$ & $4(12.1)$ & 0.8 \\
\hline \multicolumn{5}{|l|}{ HIV characteristics } \\
\hline WHO clinical stage ${ }^{* *}$ & & & & 0.01 \\
\hline Stage I & $66(41.0)$ & $55(43.0)$ & $11(33.3)$ & \\
\hline Stage II & $54(33.5)$ & $47(36.7)$ & $7(21.2)$ & \\
\hline Stage III & $38(23.6)$ & $25(19.5)$ & $13(39.4)$ & \\
\hline Stage IV & $3(1.9)$ & $1(0.8)$ & $2(6.1)$ & \\
\hline HIV-RNA >300 copies/mL** & $154(96.9)$ & $121(96.0)$ & $33(100)$ & 0.6 \\
\hline HIV-RNA, $\log _{10}$ copies $/ \mathrm{mL}^{*^{\dagger \dagger}}$ & $5.05(4.52-5.50)$ & $4.98(4.50-5.36)$ & $5.35(4.68-5.73)$ & 0.05 \\
\hline $\mathrm{CD} 4+$ cell count, $/ \mathrm{mm}^{3} *$ & $312(223-430)$ & $327(250-438)$ & 268 (183-369) & 0.02 \\
\hline Initial antiretroviral treatment** & & & & 0.7 \\
\hline $\mathrm{TDF}+\mathrm{FTC}+\mathrm{EFV}$ & $58(36.0)$ & $48(37.5)$ & $10(30.3)$ & \\
\hline $\mathrm{TDF}+\mathrm{FTC}+\mathrm{LPV} / \mathrm{r}$ & $19(11.8)$ & $16(12.5)$ & $3(9.1)$ & \\
\hline TDF+FTC+AZT & $8(5.0)$ & $7(5.5)$ & $1(3.0)$ & \\
\hline$L A M+A Z T+E F V$ & $67(41.6)$ & $51(39.8)$ & $16(48.5)$ & \\
\hline$L A M+A Z T+I D V / r$ & $7(4.4)$ & $5(3.9)$ & $2(6.1)$ & \\
\hline$L A M+A Z T+L P V / r$ & $2(1.2)$ & $1(0.8)$ & $1(3.0)$ & \\
\hline \multicolumn{5}{|l|}{ HBV characteristics } \\
\hline HBV-DNA >12 copies/mL** & $121(75.2)$ & $88(68.8)$ & $33(100)$ & $<0.001$ \\
\hline HBV-DNA, $\log _{10}$ copies $/ \mathrm{mL}^{*^{+\dagger}}$ & $4.17(3.14-7.57)$ & $3.36(3.03-5.09)$ & $8.34(7.54-8.56)$ & 0.0001 \\
\hline $\begin{array}{l}\text { HBV-DNA }>7.0 \log _{10} \\
\text { copies } / \mathrm{mL}^{* *}\end{array}$ & $41(33.9)$ & $12(13.6)$ & $29(87.9)$ & $<0.001$ \\
\hline HBV genotype $[\mathrm{N}=93]^{* *}$ & & & & 0.4 \\
\hline$A$ & $1(1.1)$ & 0 & $1(3.0)$ & \\
\hline $\mathrm{E}$ & $92(98.9)$ & $60(100)$ & $32(97.0)$ & \\
\hline $\operatorname{ALT}[\mathrm{N}=145], \mathrm{IU} / \mathrm{mL}^{*}$ & $25(17-38)$ & $25(16-37)$ & $28(20-45)$ & 0.4 \\
\hline AST $[\mathrm{N}=74], \mathrm{IU} / \mathrm{mL}^{*}$ & $36(28-48)$ & $33(26-43)$ & $45(32-69)$ & 0.04 \\
\hline ALT or AST $>40 \mathrm{IU} / \mathrm{mL}^{* *}$ & $49(30.4)$ & $35(27.3)$ & $14(42.4)$ & 0.09 \\
\hline
\end{tabular}

*Median (IQR). ${ }^{* *}$ Number (\%).

${ }^{\dagger}$ Significance between treatment groups determined using Kruskal-Wallis test for continuous variables and Pearson $\chi^{2}$ test or Fisher's exact test for categorical variables.

${ }^{+\dagger}$ Only among patients with detectable HIV or HBV viremia. 
Abbreviations: ALT, alanine aminotransferase; AST, aspartate aminotransferase; AZT, zidovudine; BMI, body mass index; EFV, efavirenz; FTC, emtricitabine; HBeAg, hepatitis B "e" antigen; HBV, hepatitis B virus; HIV, human immunodeficiency virus; IDV/r, ritonavir-boosted indinavir; LAM, lamivudine; LPV/r, ritonavir-boosted lopinavir; TDF, tenofovir; WHO, World Health Organization. 
Table 2. Comparison of patients with and without HBeAg-seroclearance

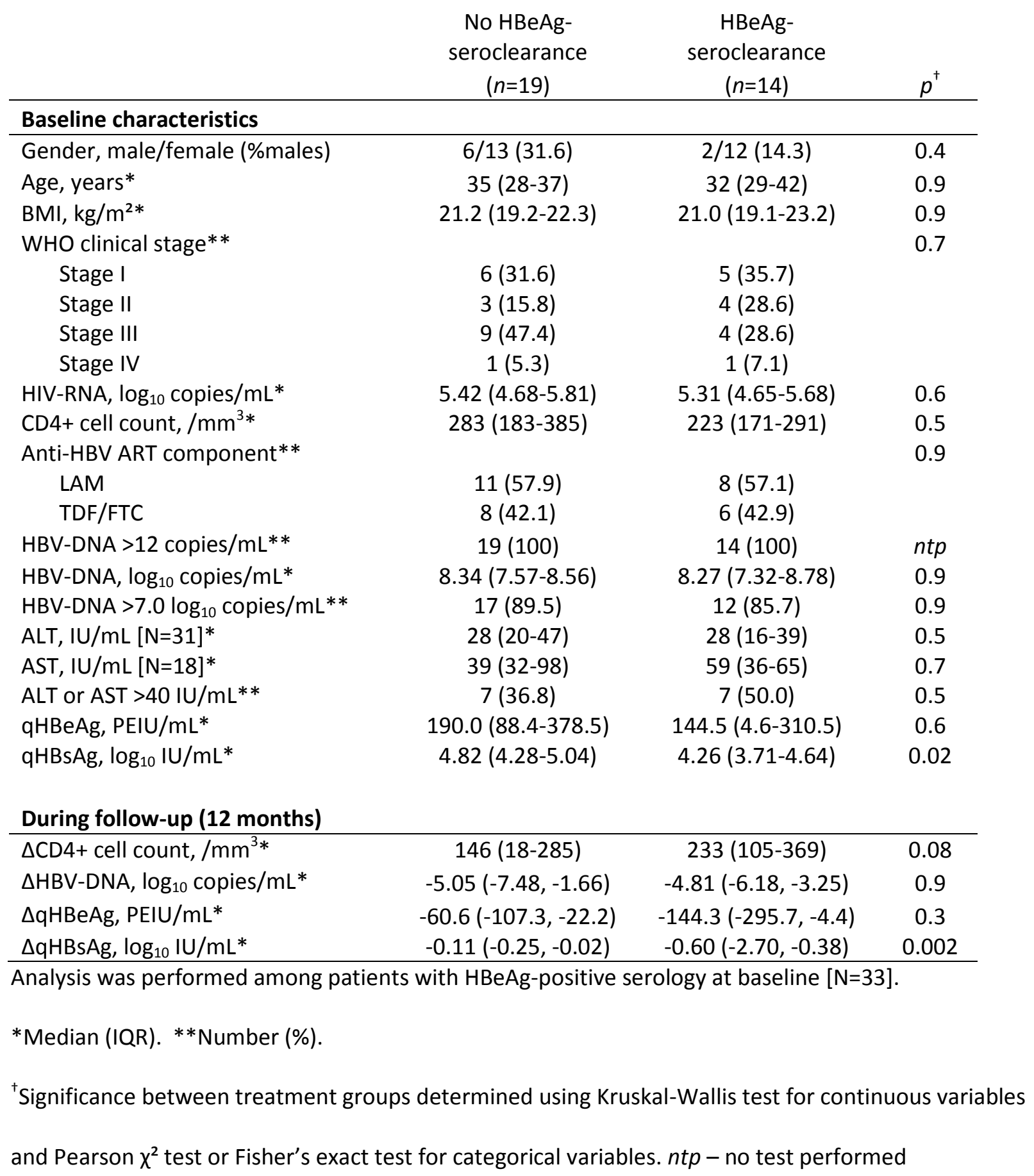


Table 3. Comparison of patients with and without HBsAg-seroclearance

\begin{tabular}{|c|c|c|c|c|c|c|}
\hline & \multicolumn{2}{|c|}{ HBeAg-positive ( $\mathrm{N}=33$ ) } & & \multicolumn{2}{|c|}{ HBeAg-negative $(\mathrm{N}=128)$} & \multirow[b]{2}{*}{$p^{+}$} \\
\hline & $\begin{array}{l}\text { No seroclearance } \\
(n=28)\end{array}$ & $\begin{array}{c}\text { Seroclearance } \\
(n=5)\end{array}$ & & $\begin{array}{c}\text { No seroclearance } \\
(n=123)\end{array}$ & $\begin{array}{c}\text { Seroclearance } \\
(n=5)\end{array}$ & \\
\hline \multicolumn{7}{|l|}{ Baseline characteristics } \\
\hline Gender, male/female (\%males) & $6 / 22(21.4)$ & $2 / 3(40.0)$ & 0.6 & $42 / 81(34.2)$ & $4 / 1(80.0)$ & 0.06 \\
\hline Age, years* & $34(28-36)$ & $42(32-43)$ & 0.08 & $35(30-41)$ & $44(37-47)$ & 0.15 \\
\hline BMI, $\mathrm{kg} / \mathrm{m}^{2 *}$ & $21.1(18.9-22.9)$ & $20.0(19.1-21.1)$ & 0.5 & $21.9(19.6-25.0)$ & $19.0(18.8-19.5)$ & 0.07 \\
\hline WHO clinical stage** & & & 0.3 & & & 0.9 \\
\hline Stage I/II & $14(50.0)$ & $4(80.0)$ & & $98(79.7)$ & $4(80.0)$ & \\
\hline Stage III/IV & $14(50.0)$ & $1(20.0)$ & & $25(20.3)$ & $1(20.0)$ & \\
\hline HIV-RNA, $\log _{10}$ copies/mL* & $5.38(4.78-5.72)$ & $5.27(4.51-5.73)$ & 0.9 & $4.94(4.41-5.29)$ & $5.67(5.35-6.44)$ & 0.05 \\
\hline $\mathrm{CD} 4+$ cell count, $/ \mathrm{mm}^{3} *$ & $279(190-385)$ & $171(148-268)$ & 0.11 & $326(251-433)$ & $390(248-448)$ & 0.7 \\
\hline Anti-HBV ART component** & & & 0.9 & & & 0.4 \\
\hline LAM & $16(57.1)$ & $3(60.0)$ & & $56(45.5)$ & $1(20.0)$ & \\
\hline TDF/FTC & 12 (42.9) & $2(40.0)$ & & $67(54.5)$ & $4(80.0)$ & \\
\hline HBV-DNA >12 copies/mL** & $28(100)$ & $5(100)$ & $n t p$ & $83(67.5)$ & $5(100.0)$ & 0.3 \\
\hline HBV-DNA, $\log _{10}$ copies/mL* & $8.45(7.68-8.76)$ & $7.21(5.57-7.93)$ & 0.02 & $3.04(0.30-3.73)$ & $3.83(3.09-4.40)$ & 0.14 \\
\hline HBV-DNA >7.0 $\log _{10}$ copies $/ \mathrm{mL}^{* *}$ & $26(92.9)$ & $3(60.0)$ & 0.1 & $11(8.9)$ & $1(20.0)$ & 0.4 \\
\hline ALT, IU/mL [N=145]* & $29(20-46)$ & $19(13-26)$ & 0.12 & $25(16-37)$ & $35(25-53)$ & 0.18 \\
\hline AST, IU/mL [N=74]* & $47(32-92)$ & $43(29-69)$ & 0.9 & $33(25-42)$ & $46^{++}$ & $n t p$ \\
\hline ALT or AST $>40 \mathrm{IU} / \mathrm{mL}^{* *}$ & $12(42.9)$ & $2(40.0)$ & 0.9 & $33(26.8)$ & $2(40.0)$ & 0.6 \\
\hline $\mathrm{qHBeAg}, \mathrm{PEIU} / \mathrm{mL}^{*}$ & $183.0(87.7-355.4)$ & $125.6(4.6-1140.5)$ & 0.9 & -- & - & \\
\hline $\mathrm{qHBsAg}, \log _{10} \mathrm{IU} / \mathrm{mL}^{*}$ & $4.63(4.26-4.96)$ & $2.64(1.75-4.08)$ & 0.03 & $3.87(3.36-4.12)$ & $-0.29(-0.92-0.16)$ & 0.0003 \\
\hline \multicolumn{7}{|l|}{ During follow-up (12 months) } \\
\hline$\Delta \mathrm{CD} 4+$ cell count, $/ \mathrm{mm}^{3} *$ & $154(48-277)$ & $344(276-369)$ & 0.04 & $154(45-275)$ & $125(109-161)$ & 0.6 \\
\hline$\Delta$ HBV-DNA, $\log _{10}$ copies/mL* & $-5.20(-6.71,-1.74)$ & $-4.34(-5.27,-3.54)$ & 0.9 & $-1.69(-3.06,0)$ & $-3.53(-4.10,-2.79)$ & 0.04 \\
\hline$\triangle \mathrm{qHBeAg}, \mathrm{PEIU} / \mathrm{mL}^{*}$ & $-68.8(-171.5,-21.3)$ & $-125.5(-754.4,-4.4)$ & 0.6 & -- & -- & \\
\hline$\triangle \mathrm{qHBsAg}, \log _{10} \mathrm{IU} / \mathrm{mL}^{*}$ & $-0.18(-0.65,-0.03)$ & $-3.05(-3.94,-0.53)$ & 0.006 & $0.00(-0.08,0.07)$ & $-1.01(-1.46,-0.37)$ & 0.0004 \\
\hline
\end{tabular}

*Median (IQR). ${ }^{* *}$ Number (\%). 
${ }^{\dagger}$ Significance between treatment groups determined using Kruskal-Wallis test for continuous variables and Pearson $\chi^{2}$ test or Fisher's exact test for categorical variables. $n t p-$ no test performed ${ }^{\text {t+ }}$ Only one value available. 


\section{Table 4. Predicting HBsAg-seroclearance using time-dependent classification probabilities during anti-HBV containing antiretroviral treatment}

Classification probabilities and predictive values $\pm \mathrm{SE}^{*}$

\begin{tabular}{|c|c|c|c|c|c|c|c|c|c|}
\hline \multirow[b]{3}{*}{ Criteria } & \multirow[b]{3}{*}{$\mathrm{n} / \mathrm{N}^{* *}(\%)$} & \multirow{2}{*}{\multicolumn{4}{|c|}{ Month-24 $(n=131)$}} & \multirow{2}{*}{\multicolumn{4}{|c|}{ Month-36 (n=95) }} \\
\hline & & & & & & & & & \\
\hline & & $\mathrm{Se}$ & $\mathrm{Sp}$ & PPV & NPV & Se & Sp & PPV & NPV \\
\hline \multicolumn{10}{|l|}{ HBsAg level at baseline } \\
\hline$\leq 10,000 \mathrm{IU} / \mathrm{mL}$ & 8/83 (9.6) & $0.78 \pm 0.14$ & $0.49 \pm 0.05$ & $0.09 \pm 0.03$ & $0.97 \pm 0.02$ & $0.80 \pm 0.13$ & $0.80 \pm 0.18$ & $0.24 \pm 0.17$ & $0.98 \pm 0.01$ \\
\hline$\leq 1,000 \mathrm{IU} / \mathrm{mL}$ & $8 / 25(32.0)$ & $0.78 \pm 0.14$ & $0.88 \pm 0.03$ & $0.31 \pm 0.10$ & $0.98 \pm 0.01$ & $0.80 \pm 0.13$ & $0.80 \pm 0.18$ & $0.24 \pm 0.17$ & $0.98 \pm 0.01$ \\
\hline$\leq 100 \mathrm{IU} / \mathrm{mL}$ & $6 / 12(50.0)$ & $0.55 \pm 0.17$ & $0.95 \pm 0.02$ & $0.45 \pm 0.16$ & $0.97 \pm 0.01$ & $0.61 \pm 0.16$ & 1.00 & 1.00 & $0.97 \pm 0.01$ \\
\hline \multicolumn{10}{|l|}{ HBsAg level at 12-months } \\
\hline$\leq 100 \mathrm{IU} / \mathrm{mL}$ & 9/19 (47.4) & $0.88 \pm 0.11$ & $0.93 \pm 0.02$ & $0.45 \pm 0.12$ & $0.99 \pm 0.01$ & $0.90 \pm 0.10$ & 1.00 & 1.00 & $0.99 \pm 0.01$ \\
\hline$\leq 10 \mathrm{IU} / \mathrm{mL}$ & $9 / 13(69.2)$ & $0.88 \pm 0.11$ & $0.97 \pm 0.02$ & $0.68 \pm 0.15$ & $0.99 \pm 0.01$ & $0.90 \pm 0.10$ & 1.00 & 1.00 & $0.99 \pm 0.01$ \\
\hline \multicolumn{10}{|l|}{ Decline of HBsAg at 12 -months } \\
\hline$\geq 1.0 \log _{10} \mathrm{IU} / \mathrm{mL}$ & $6 / 12(50.0)$ & $0.65 \pm 0.16$ & $0.95 \pm 0.02$ & $0.49 \pm 0.15$ & $0.98 \pm 0.01$ & $0.57 \pm 0.16$ & 1.00 & 1.00 & $0.97 \pm 0.02$ \\
\hline$\geq 2.0 \log _{10} \mathrm{IU} / \mathrm{mL}$ & $4 / 7(57.1)$ & $0.43 \pm 0.17$ & $0.97 \pm 0.02$ & $0.51 \pm 0.19$ & $0.96 \pm 0.02$ & $0.38 \pm 0.15$ & 1.00 & 1.00 & $0.95 \pm 0.02$ \\
\hline HBV-DNA $>12$ copies $/ \mathrm{mL}$ at baseline & $10 / 121(100)$ & 1.00 & $0.22 \pm 0.04$ & $0.08 \pm 0.03$ & 1.00 & 1.00 & $0.80 \pm 0.18$ & $0.28 \pm 0.19$ & 1.00 \\
\hline HBV-DNA $>12$ copies $/ \mathrm{mL}$ at 12 -months & $8 / 108(7.4)$ & $0.78 \pm 0.14$ & $0.40 \pm 0.05$ & $0.08 \pm 0.03$ & $0.96 \pm 0.03$ & $0.80 \pm 0.13$ & $0.40 \pm 0.22$ & $0.09 \pm 0.04$ & $0.96 \pm 0.03$ \\
\hline HBeAg-positive at baseline & $5 / 33(15.2)$ & $0.54 \pm 0.17$ & $0.85 \pm 0.03$ & $0.19 \pm 0.08$ & $0.97 \pm 0.02$ & $0.47 \pm 0.16$ & $0.80 \pm 0.18$ & $0.15 \pm 0.13$ & $0.95 \pm 0.02$ \\
\hline 12 -month change in CD4+>200/mm $\mathrm{mm}^{3}$ & $5 / 62(8.1)$ & $0.55 \pm 0.17$ & $0.62 \pm 0.05$ & $0.09 \pm 0.04$ & $0.95 \pm 0.02$ & $0.48 \pm 0.16$ & $0.80 \pm 0.18$ & $0.16 \pm 0.13$ & $0.95 \pm 0.02$ \\
\hline
\end{tabular}

*All 161 HIV-hepatitis B virus (HBV) co-infected patients were included in analysis. However, since sensitivity (Se), specificity (Sp), positive predictive value

(PPV) and negative predictive value (NPV) are in function of Kaplan-Meier survival probabilities, the number of patients considered [i.e., those not lost to

follow-up or having hepatitis B surface antigen (HBsAg)-seroclearance] during each time-interval has been included. Standard errors (SE) of each estimator are also provided.

${ }^{* *}$ Number with antigen loss $(n)$ over total number of patients with the given criteria $(N)$. A total of ten patients had HBsAg-seroclearance in the study population. All HBsAg-seroclearance events occurred within the first 24 months and thus these values did not change while extending follow-up. In contrast, classification probabilities and predictive values do depend on patient follow-up and could change at later time-points. 
Figure 1.

A

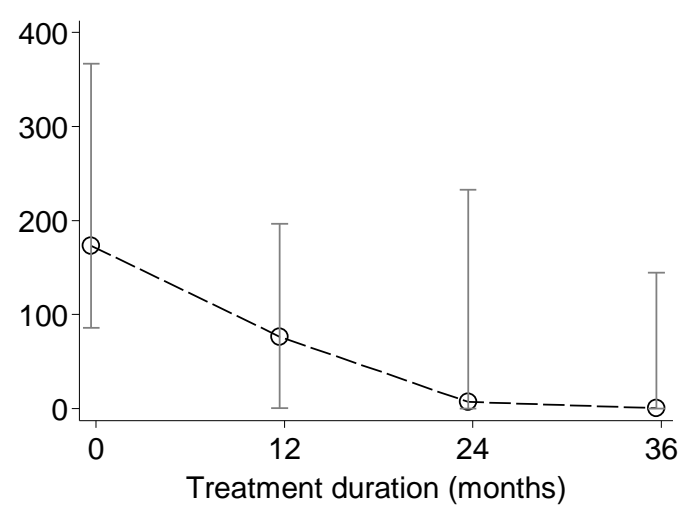

$n$

33

32

27

20

B

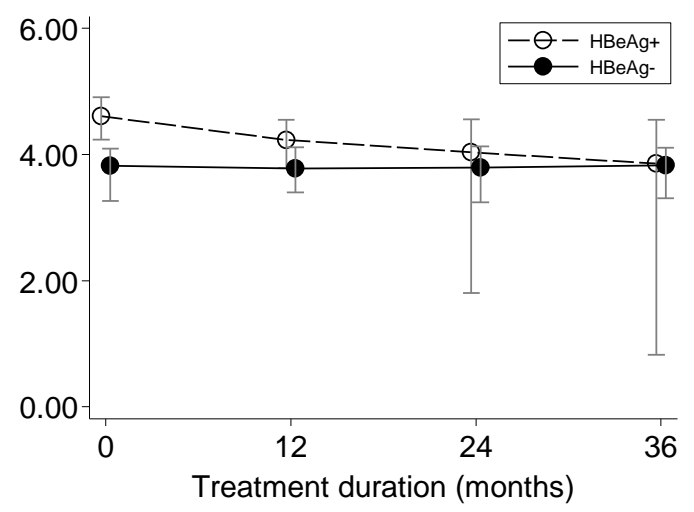

$n$

$\begin{array}{lllll}\mathrm{HBeAg}+ & 33 & 32 & 27 & 20\end{array}$

$\mathrm{HBeAg}-$

105

20
78

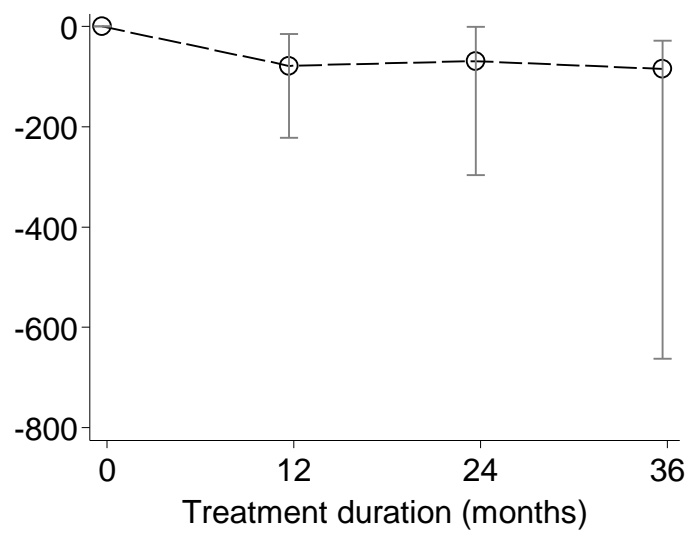

33

32

27

20

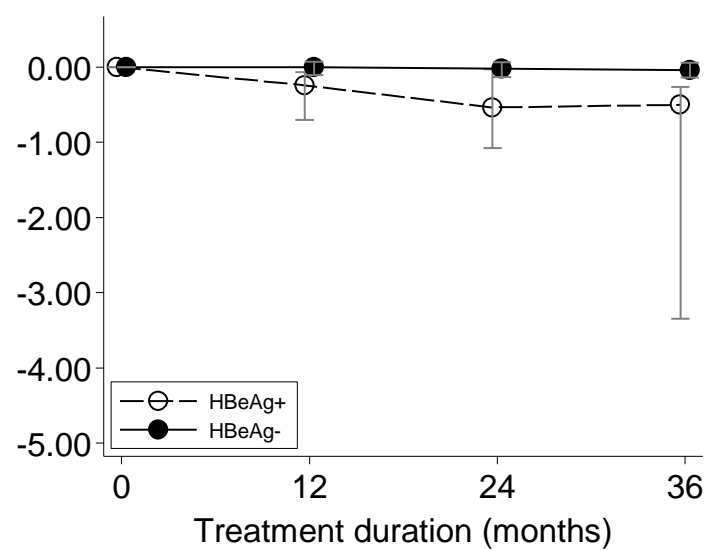

$n$

$\begin{array}{llccc}\mathrm{HBeAg}+ & 33 & 32 & 27 & 20 \\ \mathrm{HBeAg}- & 128 & 118 & 105 & 78\end{array}$ $\mathrm{HBeAg}$ -
105 
Figure 2.

A

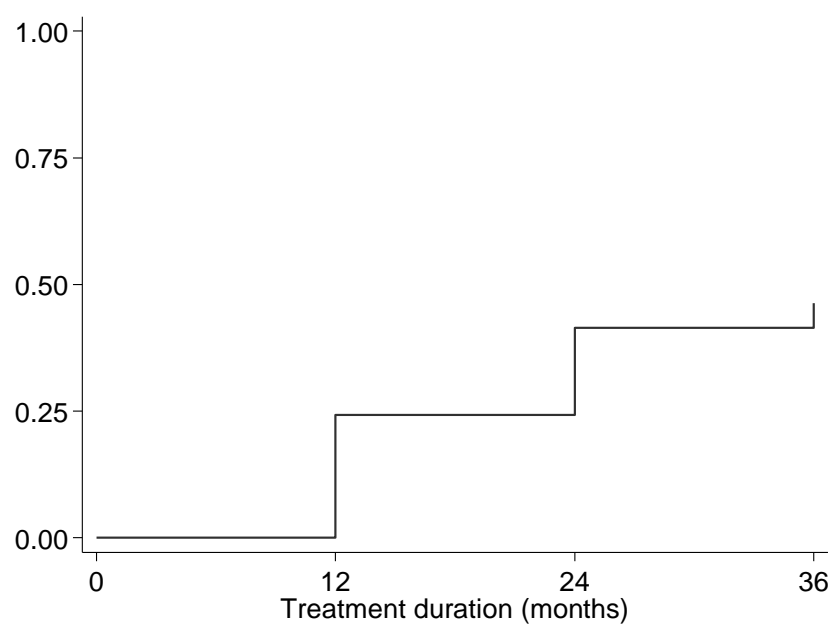

B

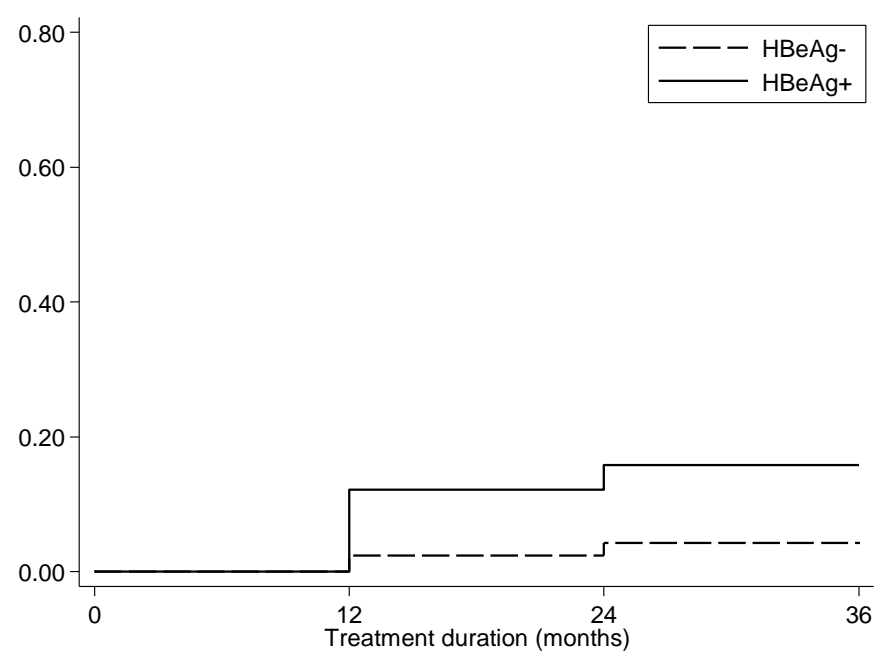

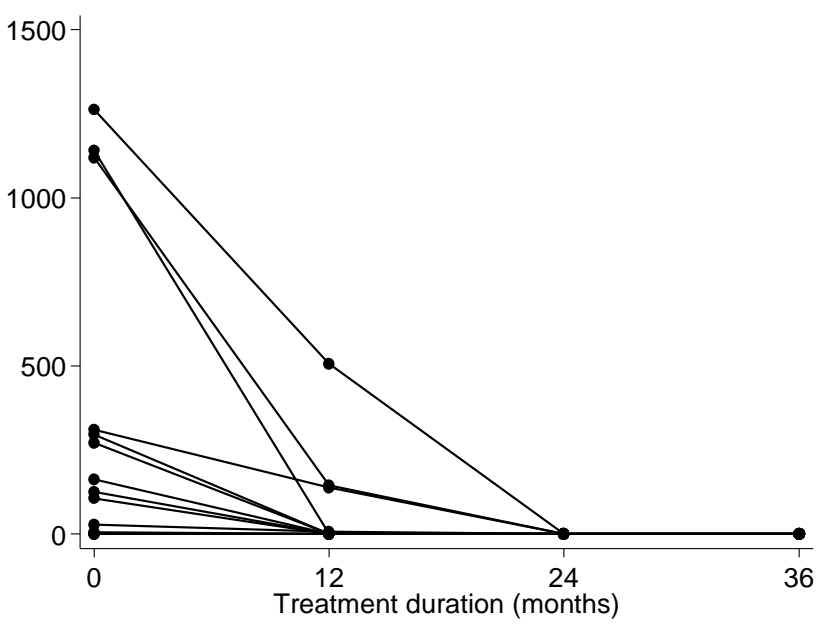

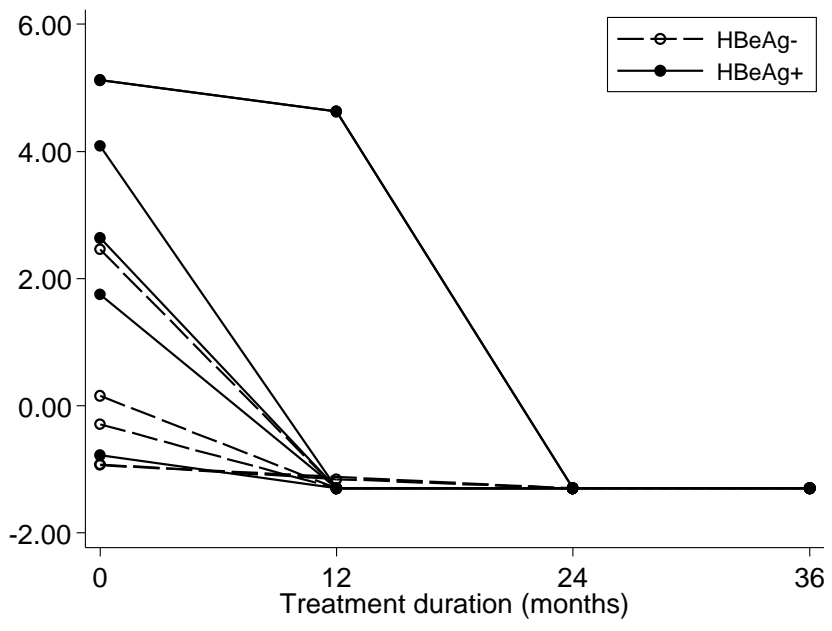

